\title{
Review of residential urban water end-use modelling
}

\author{
$\underline{\text { K. Rathnayaka }}^{\text {a }}$, H. Malano ${ }^{\text {a }}$, S. Maheepala ${ }^{\text {b }}$, B. Nawarathna ${ }^{a}$, B. George a ${ }^{\text {and M. Arora }}{ }^{\text {a }}$ \\ ${ }^{a}$ Department of Infrastructure Engineering, Melbourne School of Engineering, University of Melbourne, \\ Victoria, 3010 \\ ${ }^{b}$ CSIRO Land and Water, Highett, Victoria, 3190 \\ Email: k.rathnayaka@student.unimelb.edu.au
}

\begin{abstract}
The aim of Integrated Urban Water Management (IUWM) is to provide a sustainable approach to plan and manage urban water systems. A key consideration of IUWM is to match water demands to sources of appropriate quality and quantity (i.e. supply water to fit-for-purpose). This enables use of a wide range of water sources such as grey water, roof water, stormwater, recycled water, groundwater and surface water at different spatial scales. Availability of some water sources, in particular roof water and stormwater can vary diurnally and such sources are commonly used at local scales (i.e. allotment and development). Understanding temporal and spatial variability of water demands at individual end-use scale is essential for the optimal use of alternative water sources. This understanding invariably leads to optimal use of decentralised sources as well. In addition, consideration of spatial and temporal variability of individual end uses improves the effectiveness of demand management strategies, since those strategies, such as creating awareness and promoting water efficient appliances, can be implemented more effectively by knowing where and how they are being used.
\end{abstract}

End-use modelling is an approach for quantifying and predicting water demands of individual end uses using the relationships built on the data monitored at individual household scale. Recent residential end-use monitoring studies indicate that water consumption of residential end uses varies significantly. The aim of this paper is to review the suitability of currently available residential end-use models to adequately represent spatial and temporal variability of urban residential water end uses in order to enable demand dynamics to be predicted at development (or precinct), city and regional scales. This is to aid the adoption of IUWM approach to urban water planning, i.e. total water cycle management planning.

The purpose of the residential end-use modelling approach is mainly to quantify residential end-uses such as toilet, garden, bath, tap, shower, dishwasher and washing machine. In general, the approach is based on the time at which water use events start and the volume for each end-use. The volume is quantified using three basic input parameters, namely frequency, flow rate and duration. These parameters are defined as a mean value, mean and standard deviation or probability distribution with or without dependence on an external variable. The parameterisation determines whether the model is stochastic or deterministic and how far it can represent spatial and temporal variability of the system.

The paper found that the ability of existing residential end-use models to simulate end-use water demands with desired spatial and temporal representation especially at larger scales (city and regional scales and daily to annual scales) is limited. This is because of the use of mean values instead all plausible values for variables, difficulty in managing the complex correlations between number of variables and the lack of sufficient data to represent relationships between individual end uses and the factors that influence water consumption of individual end uses. Therefore, a single end-use model with its basic relationship is not sufficient to describe the complexity present in urban residential water demand. Conclusions of this paper indicates the need for examining improvements to the current residential end-use modelling approach with regard to spatial and temporal representation of water use. Realistic representation of spatial and temporal variability of urban water consumption at an end-use scale enables effective use of alternative water sources such as roof water, stormwater and recycled water.

Keywords: End-use modelling, IUWM, water demand modelling 


\section{INTRODUCTION}

Integrated Urban Water Management (IUWM) is an approach to plan and manage urban water systems (i.e. water supply, wastewater and stormwater), to minimise their impact on the natural environment, to maximise their contribution to social and economic vitality and to engender overall community improvement (Maheepala and Blackmore, 2008). Unlike the traditional approach, IUWM seeks to use all water sources available in an urban area to supply "fit-for-purpose" water through the use of decentralization (Burn et al., 2011). These potential water supply sources in urban areas are available at different spatial scales. Some of them such as roof water and stormwater are generally used at dwelling and development scales whereas recycled water are being used both locally and centrally. The locally available sources are comparatively small in quantity and quite varied in availability even at sub-daily scale. To plan and manage these water supply sources, it is vital to understand the water demand in detail by various end-uses at different spatial scales (development, city and regional scales) and temporal scales (sub-daily to annual scale). This demands proper representation of spatial and temporal variability in urban residential water demand.

The spatial variability of urban residential water demand at dwelling scale has been identified as significant by recent end-use measurement campaigns (Roberts, 2005; Willis et al., 2009). The Gold Coast domestic water end-use study (Willis et al., 2009) carried out at 151 households has revealed the importance of representing the spatial heterogeneity in water demand estimations (Figure 1). Understanding the factors that influence water usage by each end-use is necessary to represent the spatial and temporal variability. Variables such as population, policy decisions (price, restrictions, awareness, rebates etc.), technology take-up rates, and climate can be identified as temporal dynamic factors, since these factors mostly have a clear trend over time. The dynamic nature of water demand determinants such as demographic factors (age, gender, culture etc.), household size, typology of dwellings, education etc. should be studied to determine observable trends of each of the factor for a given time period at a given area. However, these variables are identified for their spatial variability in urban residential water demand. According to the degree of variability in each factor, the fundamental scales for majority of spatial variables are at the single person or dwelling scale. The fundamental scales for the temporal variables are at different temporal scales. The heterogeneity evident in urban residential water demand emphasise the need of representing all these identified variables to enable simulating demand dynamics of end-use water demands.

End-use modelling is an approach for quantifying and predicting water demands of individual end uses such as shower, toilet, garden etc. These models build relationships between individual end uses and the spatial and temporal factors using the data collected at individual end-use scale. The approach is based on the amount of water use and the time at which the water use events start (see Figure 2). The aim of this paper is to review the importance, capabilities and limitations of the currently available end-use modelling methods to support IUWM in a water resource planning context, i.e. to enable realistic representation of supply and demand balance dynamics for an effective and optimal use of alternative water sources such as roof water, stormwater and recycled water. The currently available end-use models considered in this paper are: (a) Integrated Supply Demand Planning (ISDP) model- an end-use modelling sub-component (Turner et al., 2010), (b) Stochastic Demand Generator model (Duncan and Mitchell, 2008), (c) SIMDEUM model (Blokker et al. 2010), (d) The Probabilistic Behavioural Approach (Thyer et al., 2009).

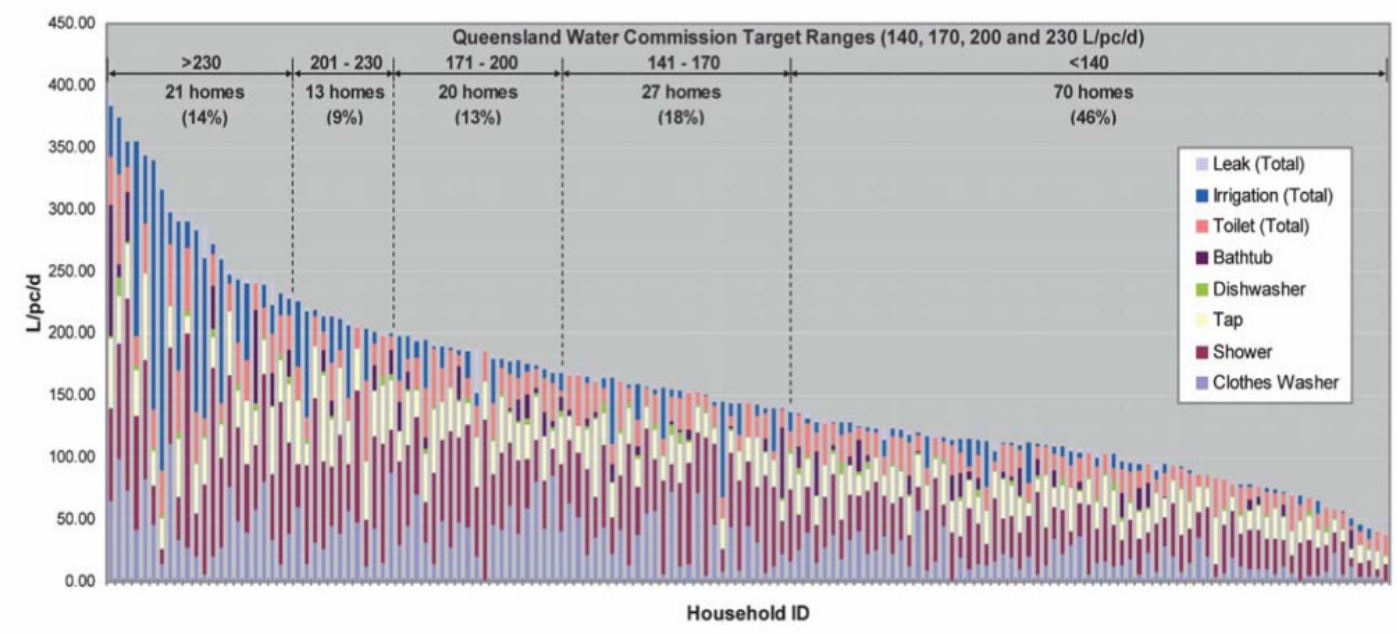

Figure 1. Household daily per capita consumption-activities break down. (Willis et al., 2009) 


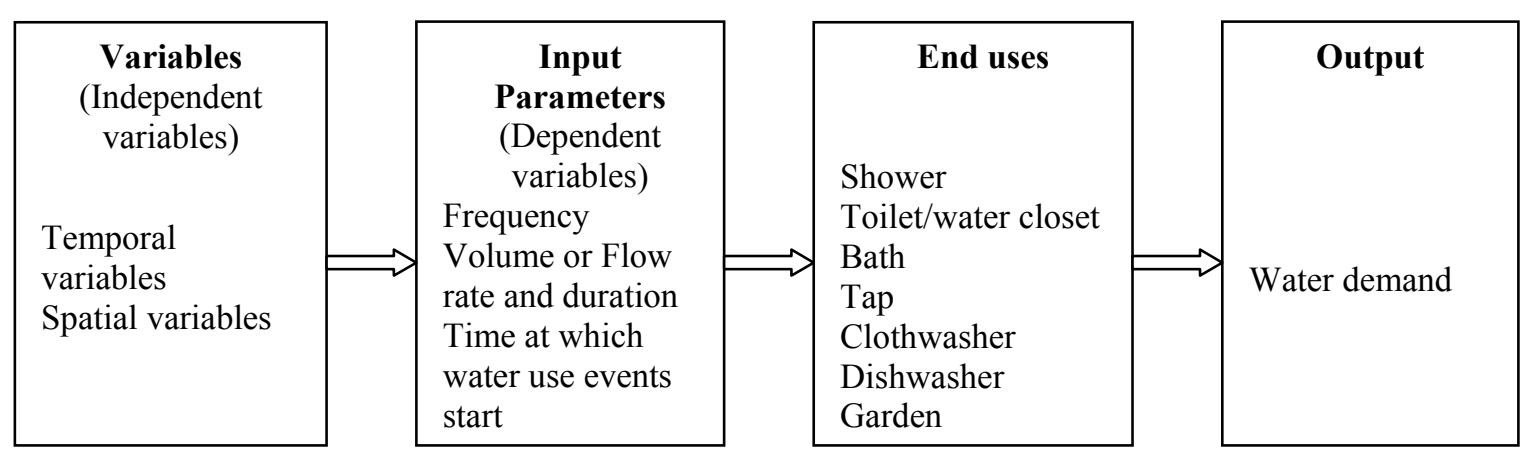

Figure 2. The basic structure of end-use modelling method

\section{EXISTING END-USE MODELS}

\section{$2.1 \quad$ ISDP Model}

The ISDP model (Turner et al., 2010) has been widely used by water utilities for demand prediction. It has two modules: baseline forecast module and a strategic forecast/options-assessment module. However, being an annual scale model, it cannot take account of sub-annual variability. Therefore, it does not provide shortterm demand outputs in daily or sub-daily scale to enable understanding of supply and demand dynamics of local sources.

\subsection{Demand Generator Model}

Duncan and Mitchell (2008) developed a stochastic demand generator model which simulates household water demands for a number of end uses at short time scales. The model generates demands at one minute time steps which is then aggregated in to 6 minute, hourly or daily time steps. The Demand Generator is to generate detailed water demands which can be used for Integrated Urban Water Management.

\subsection{The Probabilistic Behavioural Approach}

Thyer et al., (2009) presented a framework to capture both spatial and temporal variability at different scales. The framework consisted of three different levels: top level consisted of different drivers of water use (climate, attitude, policy and demography), second level consisted of parameters to capture spatial variability between households and third level captures the temporal variability of an individual house. Using this framework the authors developed a model to household indoor water use at one minute time steps probabilistically. This model is similar to Demand Generator but has improved capability of representing appliance efficiency.

\subsection{SIMDEUM Model}

Blokker et al. (2010) developed SIMDEUM to predict water demands at short time (1 s) and small spatial scales (household) based on statistical information of users and water end-uses. The model is based on probability distribution functions to estimate frequency, intensity and duration (see Table 1) and a given probability of use over the day. The model can be applied to design stage of residential developments since it is based on statistical data rather than measured flows.

\subsection{Parameterisation}

Parameterisation determines how far a model can represent spatial and temporal variability of the system and whether it is a stochastic or deterministic model. End-use modelling consists of input parameters: frequency, volume or flow rate and duration, and the time at which water use events start. The last parameter has been defined to capture the pattern of water use within a day. The spatial heterogeneity and the temporal variability beyond the sub-daily scale should be represented through rest of the parameters. These parameters are defined as a mean value, mean and standard deviation (SD), and probability distribution with or without dependence on an external variable in existing models. Table 1 shows a summary of how parameters are defined by three end-use models which are mainly discussed in this paper. 
The common end-use types those simulated by available models are shower, toilet, washing machine, dishwasher, bath, tap and garden irrigation. ISDP model is the only model that considers evaporative cooler, pool, spa and other outdoor uses such as washing cars. Roberts (2005) in his measurement campaign estimated the seasonal water use (garden irrigation, pool, evaporative cooler and spa) as $25.4 \%$ of the annual domestic water use. These end-uses result in variable seasonal peak demands due to their high variability. Roberts (2005) illustrates that average daily water use for an evaporative air conditioner was 155 liters but it can be as large as 964 liters when the temperature is more than $40^{\circ} \mathrm{C}$. For Melbourne, it is projected that by 2030 there will be 12 days over $35^{\circ} \mathrm{C}$ which was 9 days in 1990's (Garnaut, 2007). This highlights the possible impacts of climate change in these end-use water demands. Therefore, it is important to quantify water demands of these end-uses especially with the climate change and the possibility of increasing the penetration rate of these discretionary water end uses.

Blokker et al. (2010) and Thyer et al. (2009) have identified that leakage is significant in domestic water use. Studies of Yarra Valley water residential end-use monitoring and Perth domestic water use have reported that leakage accounts for about 7\% and 3\% respectively (Thyer et al., 2009). Models such as SIMDEUM and Demand Generator do not include leakage while ISDP includes this factor. Neglecting leakage can make a model difficult to calibrate. The capability to simulate all identified end-uses and leakage is important in forecasting total water demand and in planning and operational purposes.

\section{SPATIAL REPRESENTATION AND END-USE MODELLING}

The possibility of defining the parameters, frequency, volume or flow rate and duration to represent the spatial heterogeneity, makes end-use models capable of spatial representation. In contrast to traditional methods, those recently developed end-use methods have better capacity to represent key spatial variables such as household size, appliance efficiency of water use and behaviour of water users.

As an example, the Demand Generator and SIMDEUM have considered the effect of household size on water demand incorporating the relationship between household size and frequency of water use for several enduses. The relationship used in Demand Generator to estimate the frequency of dishwasher and washing machine is aligned with the finding that the increase in water use is often not linearly proportional to the increase in household size (Arbués et al., 2000).

Next, end-use modelling enables estimation of the impact of appliance efficiency of water use which has been identified as significant (Gato, 2006; Roberts, 2005; Arbues et al., 2003). SIMDEUM uses an additional input parameter named "penetration rate" to represent availability of household appliances (e.g. dishwasher) and different efficiency types (e.g. low cistern and high cistern in toilet flushing). The available end-use models represent the variability among appliances using the flow rate and the volume by defining those parameters depending on the efficiency type.

Finally, existing models represent spatial variability of residential water demand using probability distributions or mean and standard deviations. These are used where underlying spatial variables are not identified and/or difficult to predict. This can represent unobserved behavioural variability among water users. The user behaviour is difficult to understand, predict and depends on many factors such as gender, age, culture, education, and attitudes, some of which are qualitative and difficult to measure. SIMDEUM defines the frequency of toilet use (water closet) as probability distributions depending on the age of users. This allows spatial representation of the variability in both age of users and other non-specified variables such as behaviour of users. These capabilities improve the spatial representation of end-use modelling methods compared with methods based on aggregated time series data. As a result, SIMDEUM has shown a good match of simulated outputs to measurement data for a single household and the sum of 43 households. It is an evidence of its capacity to predict end-use water demands at dwelling and development scales. However, a good match between observed data and simulation results on a small time or spatial scale does not assure a good match on longer time or larger spatial scales (Blokker et al., 2010). 
Table 1. Parameterisation used in different end-use models

\begin{tabular}{|c|c|c|c|c|c|c|c|c|c|}
\hline \multirow[t]{2}{*}{ Name of the model } & \multirow{2}{*}{$\begin{array}{l}\text { Input } \\
\text { parameter }\end{array}$} & \multicolumn{8}{|c|}{ Common end-uses simulated in end-use modelling methods } \\
\hline & & Toilet & Shower & $\begin{array}{l}\text { Washing } \\
\text { machine }\end{array}$ & Dishwasher & Bath & Tap & & Garden \\
\hline \multirow{5}{*}{$\begin{array}{l}\text { ISDP model, the end-use } \\
\text { modelling sub } \\
\text { component. } \\
\text { (Integrated resource } \\
\text { planning for urban water, } \\
\text { 2011) }\end{array}$} & \multirow[t]{2}{*}{ Frequency } & \multirow[t]{2}{*}{ Mean } & \multirow[t]{2}{*}{ Mean } & \multirow{2}{*}{$\begin{array}{l}\text { Mean }^{\mathrm{h}} \text { (single \& } \\
\text { multi-family) }\end{array}$} & \multirow{2}{*}{$\begin{array}{l}\text { Mean }^{\mathrm{h}} \text { (single \& } \\
\text { multi-family) }\end{array}$} & \multirow{2}{*}{$\begin{array}{l}\text { Mean }^{\mathrm{b}}(<\text { age- } \\
\left.12 \mathrm{yrs}^{2}>12 \text { yrs }\right)\end{array}$} & Sink & Basin & \multirow[t]{2}{*}{$\mathrm{N} / \mathrm{A}^{\mathrm{a}}$} \\
\hline & & & & & & & Mean & Mean & \\
\hline & Flow rate & - & $\begin{array}{l}\text { Mean }^{\mathrm{e}} \\
\text { (efficient\& } \\
\text { inefficient) }\end{array}$ & - & - & - & - & Mean & $\mathrm{N} / \mathrm{A}^{\mathrm{a}}$ \\
\hline & Duration & - & Mean value & - & - & - & - & Mean & $\mathrm{N} / \mathrm{A}^{\mathrm{a}}$ \\
\hline & Volume & Mean $^{e}$ & - & Mean & Mean & $\begin{array}{l}\text { Fix value } \mathrm{e}^{\mathrm{b}} \\
\text { for }<\&>12 \mathrm{yrs}\end{array}$ & Mean & - & $\mathrm{N} / \mathrm{A}^{\mathrm{a}}$ \\
\hline \multirow{4}{*}{$\begin{array}{l}\text { Demand Generator } \\
\text { (Duncan \& Mitchel, 2008) }\end{array}$} & Frequency & $\begin{array}{l}\text { Mean for full \& } \\
\text { half flush }\end{array}$ & Typical No. & $\begin{array}{l}\text { Function of } \\
\text { household size }\end{array}$ & $\begin{array}{l}\text { Function of } \\
\text { household size }\end{array}$ & Typical No. & \multicolumn{2}{|c|}{ Function of household size } & Fix value $^{i}$ \\
\hline & Flow rate & $x$ & Mean \& SD & User specified & User specified & User specified & \multicolumn{2}{|l|}{-} & Mean \& SD \\
\hline & Duration & - & $\begin{array}{l}\text { Probability } \\
\text { distribution }\end{array}$ & & $\begin{array}{l}\text { User specified } \\
<30 \text { minutes }\end{array}$ & $\begin{array}{l}\text { User specified } \\
<12 \text { minutes }\end{array}$ & \multicolumn{2}{|l|}{-} & $\begin{array}{l}\text { Probability } \\
\text { distribution }\end{array}$ \\
\hline & Volume & $\begin{array}{l}\text { Mean \& SD for } \\
\text { full \& half flush }\end{array}$ & - & $\begin{array}{l}\text { Fix values for } \\
\text { front } \& \text { top } \\
\text { loaders }\end{array}$ & Fix value & $\begin{array}{l}\text { User specified } \\
\text { value }\end{array}$ & \multicolumn{2}{|c|}{ User specified Mean } & - \\
\hline \multirow{4}{*}{$\begin{array}{l}\text { SIMDEUM } \\
\text { (Blokker et al., 2010) }\end{array}$} & \multirow[t]{2}{*}{ Frequency } & \multirow[t]{2}{*}{$\begin{array}{l}\text { Poison distribution } \\
\mathrm{b}\end{array}$} & \multirow[t]{2}{*}{$\begin{array}{l}\text { Binomial } \\
\text { distribution }\end{array}$} & \multirow[t]{2}{*}{$\begin{array}{l}\text { Poison } \\
\text { distribution }{ }^{\mathrm{g}}\end{array}$} & \multirow[t]{2}{*}{$\begin{array}{l}\text { Poison } \\
\text { distribution }^{\mathrm{g}}\end{array}$} & \multirow[t]{2}{*}{$\begin{array}{l}\text { Poison } \\
\text { distribution }\end{array}$} & Kitchen & Bathroom & \multirow[t]{2}{*}{$\begin{array}{l}\text { Poisson } \\
\text { distribution }\end{array}$} \\
\hline & & & & & & & $\begin{array}{l}\text { Negative } \\
\text { binomial } \\
\text { distribution }\end{array}$ & $\begin{array}{l}\text { Poisson } \\
\text { distribution. }\end{array}$ & \\
\hline & Flow rate & Fixed $^{e}$ & Fixed $^{\mathrm{C}}$ & Specific pattern & Specific pattern & Fixed & Uniform $^{f}$ & Uniform $^{f}$ & Uniform $^{\mathrm{e}}$ \\
\hline & Duration & Fixed $^{d}$ & $\begin{array}{l}\text { chi-square } \\
\text { distribution }\end{array}$ & Specific pattern & Specific pattern & Fixed & $\begin{array}{l}\text { Log-normal } \\
\text { distribution }\end{array}$ & $\begin{array}{l}\text { Log-normal } \\
\text { distribution }\end{array}$ & $\begin{array}{l}\text { Log-normal } \\
\text { distribution }\end{array}$ \\
\hline
\end{tabular}

${ }^{\text {a }}$ N/A-not applicable

${ }^{\mathrm{b}}$ depends on age

${ }^{c}$ depends on type of shower head and water heater

d function of inlet flow \& bowl volume

depends on the appliance type

${ }^{\mathrm{f}}$ functions of pressure \& internal resistance of the indoor plumbing

${ }^{g}$ depends on household size

${ }^{\mathrm{h}}$ depends on typology of dwellings

${ }^{\mathrm{i}}$ depends on maximum temperature of the day
${ }^{\mathrm{j}}$ mean \& SD for appliance and another SD for user 
The spatial representation of end-use modelling at larger spatial scales and highly heterogeneous systems can be limited with the following three factors. Firstly, an input parameter defined as a fix value (e.g. mean value) results in no variation between households if it is not dependent on a variable. This will not make any difference between end-use models and lumped models eventually in terms of spatial representation. In situations where there is less variability in the data sample, a mean value may be used. As a result, that parameter will be static over space and time. Secondly, it is complex when an input parameter (e.g. frequency) depends on more than one variable. As an example, Demand Generator derives frequency of bath as a function of household size. However, frequency can also depend on age and other demographic factors which are not considered in the model. Thirdly, data plays a major role in limiting the spatial representation. End-use modelling is likely to rely on data obtained by a relatively small sample due to high cost and labour intensity of data gathering. The data unavailability at end-use level limits not only the spatial representation but also the calibration and validation of these models. Therefore, the ability of end-use modelling methods to predict demand outputs at larger spatial scales and to simulate highly heterogeneous systems can probably be limited with above constraints.

\section{TEMPORAL REPRESENTATION AND END-USE MODELLING}

Different temporal variables are significant at different temporal scales. Representation of temporal variability at one (e.g. sub-daily) scale does not represent temporal variability at other (e.g. seasonal or annual) scales. Consideration of variables that are significant at sub-daily scale to the annual scale in a single model together with spatial representation is a challenge but needed in water resource management and planning, in particular for planning aspects of decentralised systems. End-use modelling facilitates identification of water demand variability within a day with the time parameter embedded into the basic relationship. The behavioural difference among water users is the key variable at sub-daily scale and is represented through probability distributions in current end-use models (Duncan and Mitchel, 2008; Blokker et al, 2010; Thyer et al., 2009). Validation of existing models has shown their suitability in predicting enduse water demands at sub-daily scale (Duncan and Mitchel, 2008; Blokker et al, 2010).

The ability of end-use modelling to represent temporal variability beyond the sub-daily scale depends on the following factors. It is easy to represent a variable when it is the only variable which an input parameter depends on. For an instance, appliance efficiency is such a variable, as the input parameter flow rate depends significantly on appliance efficiency in most instances. The appliance efficiency is also a variable varying both spatially and temporally. Therefore, relationship with appliance efficiency of water use enables finding the impacts of both spatial and temporal variability due to that variable. This is possible with available enduse models (Duncan and Mitchel, 2008; Blokker et al, 2010). Another example is ability of SIMDEUM to use different frequency values depending on the age group of occupants in a dwelling for bath and toilet enduses. Age is a factor varies spatially and temporally. Therefore, this correlation also provides an opportunity to observe the impact of ageing population on residential water demand. Therefore, such correlations enable representing both spatial and temporal variability.

Nonetheless, it is complex when an input parameter depends on number of variables. Demand Generator has used the variable, temperature to determine the frequency of garden water use. The probability of garden watering event starting at a given time depends linearly on temperature above a calibrated minimum value (Duncan and Mitchel, 2008). Therefore, the chance of the event occurring and the frequency of the event depend on the maximum temperature of the day. This represents the temporal variability of garden water use. In addition, frequency of garden watering again varies spatially due to behaviour of water users, a factor not considered in Demand Generator. In contrast, SIMDEUM considers the spatial variability in garden water use but not the temporal variability. This explains why available end-use models have limited capacity to represent both spatial and temporal variability comprehensively.

Further, there are some other reasons for limited temporal representation in current end-use models. Data unavailability to identify relationships between temporal variables and input parameters at individual end-use scale is a one such problem. Next, input parameters defined as a mean value or fix value without dependence on a variable are static over both space and time. Therefore, those input parameters do not represent the temporal variability as discussed in section 3. Finally, probability distributions or mean and standard deviations used in end-use models do not help with describing the temporal variability beyond the sub-daily scale. Therefore, it also makes end-use modelling static.

These are the capabilities and limitations identified in end-use modelling to represent the temporal variability in urban residential end-use water demand. Therefore, the capacity to predict end-use water demands at daily, seasonal and annual scales with desired spatial representation is limited with current end-use models. 


\section{CONCLUSIONS AND RECOMMENDATIONS}

Understanding the water demand in detail is necessary in IUWM or total water cycle management planning at precinct, city and regional scales. End-use water demands at multiple scales of time and space and how these demands responds to different demand management strategies and other socio-economic changes are the key aspects to be known.

End-use modelling is an approach for quantifying and predicting water demands of individual end uses. The aim of this paper is to assess the suitability of currently available end-use models to adequately represent spatial and temporal variability of urban residential water end-uses. This is to aid the adoption of IUWM approach to urban water planning.

The review identified the ability of current end-use models to simulate sub-daily water demand patterns and to represent spatial variability at dwelling scale. However, the ability of current end-use models to simulate end-use water demands with desired spatial and temporal representation in order to enable demand dynamics to be predicted at development (or precinct), city and regional scales is limited. This is because of the use of mean values instead all plausible values for variables, difficulty in managing the complex correlations between number of variables and the lack of sufficient data to represent relationships between individual end uses and the factors that influence the water consumption of individual end uses.

Therefore, a single end-use model with its basic relationship is not sufficient to describe the complexity of urban residential water demand. Improvements are needed in representing spatial and temporal variability of urban residential water end-use demand. Realistic representation of spatial and temporal variability of urban water consumption at an end-use scale enables effective use of alternative water sources such as roof water, stormwater and recycled water.

\section{REFERENCES}

Arbués, F., Barberán R. and Villanúa I. (2000). Water price impact on residential water demand in the city of Zaragoza: A dynamic panel data approach. 40th European Congress of the European Regional Studies Association in Barcelona, August 30-31.

Arbués F., Garc'1a-Valiñas M.A. and Mart'inez-Espiñeira R. (2003). Estimation of residential water demand: a state-of-the-art review. Journal of Socio-Economic, 32, 81-102.

Blokker, E.J.M., Vreeburg J.H.G. and van Dijk J.C. (2010). Simulating residential water demand with stochastic end-use model. Journal of Water Resources Planning and Management, 136(1), 19-26.

Burn, S., Maheepala S. and Sharma A. K. (2011). The role of decentralization in integrated urban water management, Key note speech, Proceedings of the International Conference on Integrated Water Management, Murdoch University, Perth, Australia, February 2-5.

Duncan, H.P. and Mitchell V.G. (2008). A stochastic demand generator for domestic water use. Paper presented at Water Down Under 2008 conference, Adelaide, April 14-17.

Garnaut, R. (2007). Garnaut Climate Change Review, http://www.garnautreview.org.au/2008-review.html [Assessed 01 ${ }^{\text {st }}$ July, 2011]

Gato, S. (2006). Forecasting urban residential water demand. PhD. thesis, Royal Melbourne Institute of Technology University, Melbourne.

Maheepala S. and Blackmore J. (2008). Integrated urban water management for cities. In transition: pathways towards sustainable urban development in Australia. Edited by P.W. Newton. CSIRO publishing, 461-478.

Thyer, M.A., Duncan H., Coombes P., Kuczera G. and Micevski T. (2009). A probabilistic behavioral approach for the dynamic modelling of indoor household water use. Paper presented at 32nd Hydrology and Water Resources Symposium, Newcastle, Australia, 30th November -3rd December.

Turner, A., Willets J., Fane S., Giurco D., Chong J., Kazaglis A., and White S., (2010). Guide to demand management and integrated resource planning. Prepared by the Institute for Sustainable Futures, University of Technology Sydney for the National Water Commission and the Water Services Association of Australia, Inc.

Integrated resource planning for urban water, Models and tools, Integrated Supply-Demand Planning (ISDP) Model by Institute for Sustainable Futures, University of Technology, Sydney and CSIRO, http://www.urbanwaterirp.net.au/index.php?option=com content $\&$ view $=$ article $\&$ id $=58 \&$ Itemid $=68$ [Assessed 15 ${ }^{\text {th }}$ March, 2011]

Roberts, P. (2005). Yarra valley water 2004 residential end-use measurement study. Yarra Valley Water, Melbourne, Australia.

Willis R., Stewart R.A., Panuwatwanich K., Capati B. and Giurco D. (2009). Gold Coast domestic water end use study. Journal of the Australian water Association,36(6), 79-85. 